\title{
Heterogeneous Response to Calcium by Individual Parathyroid Cells
}

\author{
F. Sun, C. K. Ritchie, C. Hassager, P. Maercklein, and L. A. Fitzpatrick \\ Division of Endocrinology, Department of Medicine, Mayo Clinic and Mayo Foundation, Rochester, Minnesota 55905
}

\begin{abstract}
Classical stimulus-secretion theory suggests that each individual cell responds to a given stimulus. We tested this theory by determining the response of single bovine parathyroid cells to calcium with the reverse hemolytic plaque assay (RHPA), an assay that measures hormone release from individual cells. As calcium concentrations decreased, the amount of parathyroid hormone (PTH) released per cell increased, and cells were recruited to release PTH. To confirm that adequate stores of PTH were present, immunocytochemistry and in situ hybridization were performed. To test if cells that did not release PTH were capable of secretion, we performed a sequential RHPA; $\mathbf{4 7 . 8 \%}$ of cells did not release PTH after the first stimulus. After the second exposure to low concentrations of calcium, $\mathbf{2 6 . 5 \%}$ of these "nonsecretory" cells were able to release PTH. We conclude that parathyroid cells are homogeneous for PTH content and synthetic capability. Parathyroid cells respond to changes in extracellular calcium heterogeneously in that more PTH per cell is released, and individual parathyroid cells are "recruited" to release PTH at low calcium concentrations. In addition, parathyroid cells can be induced to secrete suggesting that cells are viable but in a depressed secretory state. Parathyroid cells may exist in an "on" or "off" secretory state. ( $J$. Clin. Invest. 1993.91:595-601.) Key words: calcium • parathyroid hormone - reverse hemolytic plaque assay • secretion • stimulus-secretion
\end{abstract}

\section{Introduction}

Classical stimulus-secretion coupling theory suggests that each cell responds to a given stimulus with the release of secretory product. However, this theory is now under scrutiny as a number of investigators are recognizing that a heterogenous secretory response to a given agonist occurs. For example, in the bovine pituitary gland, heterogeneity of the secretory response to a diversity of agonists has been described. Using the reverse hemolytic plaque assay which can detect hormone release from individual cells, Frawley et al. has demonstrated the existence of cells that secrete both growth hormone and prolactin (1). These pituitary cells respond differentially to various stimuli. Recently, Kineman and co-workers (2) identified a unique subpopulation of cells that released growth hormone after stimulation with growth hormone releasing factor but not under

\footnotetext{
Address reprint requests to Dr. L. A. Fitzpatrick, Endocrine Research Unit, Mayo Clinic, 5-164 West Joseph, Rochester, MN 55905.

Received for publication 17 September 1991 and in revised form 22 June 1992.
}

J. Clin. Invest.

(C) The American Society for Clinical Investigation, Inc. 0021-9738/93/02/0595/07 \$2.00

Volume 91, February 1993, 595-601 basal conditions. The investigators termed these cells "silent" somatotropes that release growth hormone only under stimulated conditions. In other studies, distinct subpopulations of corticotropes respond to corticotropin releasing factor and adrenocorticotropin (ACTH), underlining the complex relationship between the hypothalamus and pituitary $(3,4)$.

Recently, Porter and co-workers (5) have indicated that fully differentiated cells in the pituitary can transdifferentiate without undergoing mitosis. Acidophils can undergo a conversion from primarily secretors of growth hormone before pregnancy to prolactin releasers during lactation. The different hormone milieu that occurs in these physiologic states allows alteration of cell phenotype.

In the parathyroid gland, it has been long assumed that parathyroid cells form a homogeneous population, with an "all or none" secretory response to decreasing concentrations of calcium. Several aspects of parathyroid hormone (PTH) secretory dynamics have not been explained by these phenomena. For example, baseline release of PTH is always present, even at high ("inhibitory") calcium concentrations (6). We have utilized the reverse hemolytic plaque assay (RHPA) 1 to determine the amount of PTH per cell released in response to a given stimulus (7). In spite of adequate stores of PTH, we demonstrate in this study that recruitment of secretory cells occurs in response to low extracellular calcium.

\section{Methods}

\section{RHPA}

Adult bovine parathyroid cells were obtained from an abattoir (Ledebuhr's, Winona, MN), dispersed with trypsin, and mixed with staphylococcal protein A-linked ovine erythrocytes as previously described (7). Ovine erythrocytes (oRBC) were conjugated to protein A with chromium chloride $\left(\mathrm{CrCl}_{3} \cdot 6 \mathrm{H}_{2} \mathrm{O}\right)$. Microscope slides coated with poly-Llysine were used to form Cunningham chambers, and the protein Aconjugated $O R B C$ and parathyroid cells were infused into the chamber with a Pasteur pipette. After allowing for cell attachment, the plaque reaction was initiated by infusion of antiserum (1:35) and an appropriate secretogogue. As PTH is released, it is bound to the antiserum which, in turn, is bound to the protein A-conjugated oRBC. To develop the plaque, media containing guinea pig complement ( $1: 10$ to $1: 50$ ) is added for $20-30 \mathrm{~min}$. To inhibit the reaction and stop oRBC hemolysis, media is infused into the chamber. PTH antiserum was the generous gift of Dr. Claude Arnaud (Director, Center for Biomedical Research on Aging, San Francisco, CA ). This assay has been validated by radioimmunoassay as previously published (7).

Measurement of plaque area was made $(\times 600$ final magnification $)$ on a photomicroscope (model III, Carl Zeiss, Inc., Thornwood, NY). The presence of a plaque around a parathyroid cell identified it as a PTH-secreting cell. A plaque is defined as a clear area containing RBC ghosts which completely encircle a secretory cell and can be quantitated through image analysis techniques (Bioquant, Inc., Prior Lake,

1. Abbreviations used in this paper: FDA, fluorescein diacetate; GC, glucocorticoid; oRBC, ovine erythrocytes; PI, propidium iodide; RHPA, reverse hemolytic plaque assay. 
MN). The percentage of cells forming plaques was determined by counting the total number of parathyroid cells versus those forming plaques.

\section{Plaque formation: evaluation of cell attachment substrate} Plaque formation on gelatin substrate. To determine the effects of cell attachment on secretory response, microscope slides were subbed with $1 \%$ gelatin. The cell suspension was plated as above, in parallel with cells in the "traditional" Cunningham chamber. Cells were assessed for the percentage of plaque-forming cells as detailed above.

RHPA vs. immunochemiluminescent assay for PTH. To test the possible interference of the cell attachment substrate poly-L-lysine on PTH release, parathyroid cells were incubated in test tubes with or without solid-phase coating of poly-L-lysine. After $1 \mathrm{~h}$ at $37^{\circ} \mathrm{C}$, cell supernatant was collected for PTH assay by immunochemiluminescence (8).

\section{Cell viability}

Cell viability was tested at each point during the reverse hemolytic plaque assay. Aliquots of cells were examined immediately after trypsin digestion, after the cells were plated in the Cunningham chambers, before addition of complement, and after addition of complement. Cell viability was determined by a double-fluorescence antibody technique. Cells were exposed to fluorescein diacetate (FDA) and propidium iodide (PI). With a wide band pass excitation filter (450-490 $\mathrm{nm}$ ) and emission at $750 \mathrm{~nm}$, viable cells fluoresced green from FDA, and injured and dead cells were stained by PI, which forms a bright red fluorescent complex in the cell nucleus (9).

\section{Immunocytochemistry. on plaque-forming cells}

Immunocytochemistry was combined with the RHPA to detect cells containing PTH that may not release PTH in response to applied agonists. After incubation in complement, chambers were infused with 0.2 $\mathrm{M}$ sodium acetate in $0.5 \mathrm{M} \mathrm{NaCl}$ for $10 \mathrm{~min}$ at $4^{\circ} \mathrm{C}$. Plaques were then fixed in B-5 fixative for $10 \mathrm{~min}\left(6 \mathrm{~g} \mathrm{HgCl}_{2}\right.$ and $1.25 \mathrm{~g}$ of sodium acetate in $90 \mathrm{ml}$ of distilled $\mathrm{H}_{2} \mathrm{O}$ with the addition of $10 \mathrm{ml}$ of $37 \%$ formaldehyde immediately before use). Slides were then treated for $1 \mathrm{~min}$ in each of the following solutions in sequence: $95 \%$ ethanol, $\mathrm{H}_{2} \mathrm{O}$, Lugol's iodide ( $1 \mathrm{~g}$ of iodide, $2 \mathrm{~g}$ of sodium iodide in $100 \mathrm{ml}$ of $\mathrm{H}_{2} \mathrm{O}$ ), $\mathrm{H}_{2} \mathrm{O}$, sodium thiosulfate $\left(2 \mathrm{~g} / 100 \mathrm{ml} \mathrm{H}_{2} \mathrm{O}\right)$. After fixation, slides were treated sequentially with $3.0 \% \mathrm{H}_{2} \mathrm{O}_{2}$ for $15 \mathrm{~min}$ and normal rabbit serum for $20 \mathrm{~min}$ at room temperature. Slides were washed with phosphate-buffered saline (PBS) for $10 \mathrm{~min}$ and incubated in 1:1,000 NG-1 anti-PTH (a generous gift from Dr. L. Mallette, Baylor College of Medicine, Houston, TX) for $16 \mathrm{~h}$ at room temperature. The immunocytochemical procedure was performed using the ABC method (Vector Labs, Inc., Burlingame, CA). Slides were incubated in biotinylated antibody at room temperature for $30 \mathrm{~min}$ and washed with PBS for 10 min. Slides were then incubated in $\mathrm{ABC}$ reagents at room temperature for $30 \mathrm{~min}$ and washed with PBS for ten minutes. To develop color, slides were incubated in diaminobenzidine (Sigma Chemical Co., St. Louis, MO) as described in the $\mathrm{ABC}$ kit and washed with $\mathrm{H}_{2} \mathrm{O}$ for 5 $\mathrm{min}$. The coverslip was removed, the slide was air-dried overnight, and counted on a photomicroscope (final magnification $\times 1,000$ ). (Nikon, Inc., Melville, NY). Normal human fibroblasts were generously provided by Dr. Cheryl Conover and GC pituitary cells were provided by Dr. Norman Eberhardt (Endocrine Research Unit, Mayo Clinic and Mayo Foundation). A positive cell was identified as a cell with dark (blue-black) cytoplasm. Negative cells, such as the fibroblast and GC pituitary cells, were without any color enhancement.

\section{In situ hybridization}

Bovine parathyroid cells were dispersed and incubated in the RHPA as described above. After development of the plaque, complement-mediated cell lysis was stopped by fixation of cells. To maintain a low background for hybridization, the following tissue processing was used: cells were fixed with an infusion of $0.1 \%$ glutaldehyde $/ 3 \%$ paraformal- dehyde at room temperature for $5 \mathrm{~min}$. Cover slips were removed, and slides were placed in hybridization solutions and Coplin jars (sterilized by soaking in 0.1 diethylpyrocarbonate overnight and autoclaved). Slides were rinsed twice with PBS and placed in $0.25 \%$ acetic anhydride in $0.1 \mathrm{M}$ triethanolamine hydrochloride, $0.9 \% \mathrm{NaCl}, \mathrm{pH} 8.0$, for 10 min at room temperature. The sections were washed twice in $2 \times$ SSC, processed through graded ethanol $(70 \%, 80 \%, 95 \%$, and $100 \%), 100 \%$ chloroform, and ethanol ( $100 \%$ and $95 \%$ ), and allowed to air dry.

The slides were hybridized with $100 \mu$ l of hybridization buffer containing 1-2 $2 \times 10^{6} \mathrm{dpm} / \mathrm{ml}$ of labeled probe under a parafilm coverslip. Slides were incubated $16-24 \mathrm{~h}$ at $37^{\circ} \mathrm{C}$. Coverslips were removed by floating in $2 \times$ SSC, and sections were washed in $2 \times$ SSC-50\% formamide at $37^{\circ} \mathrm{C}$ (four times for $15 \mathrm{~min}$ ) followed by $1 \times \mathrm{SSC}$ at room temperature (two times for $30 \mathrm{~min}$ ), dipped in $\mathrm{ddH}_{2} \mathrm{O}, 70 \%$ ethanol, and dried. Oligonucleotide DNA probe ( 20 bases) from the amino-terminal portion of bovine PTH was 3'-labeled with terminal transferase and $\left[\alpha-\right.$ theo $\left.{ }^{35} \mathrm{~S}\right] \mathrm{dATP}$. Slides were dipped in nuclear emulsion (NTB, 1:1 with water, Eastman Kodak Co., Rochester, NY) and hung to dry for $5 \mathrm{~min}$. Slides were stored at $4^{\circ} \mathrm{C}$ for $10-20 \mathrm{~d}$ and emulsions developed in Kodak D-19 for $1-2 \mathrm{~min}$ at $15^{\circ} \mathrm{C}$.

Hybridization with nonsense probes and probes for transcripts other than PTH were used to determine nonspecific binding (10).

\section{Sequential RHPA}

The sequential RHPA was developed to measure repeated release of hormone from an individual cell (11); see Table I. The sequential assay differs in several respects from the RHPA described above: In stage 1, parathyroid cells were plated for the RHPA with oRBC; after addition of antiserum and complement, the reaction was stopped by infusion of media. Cells were indexed as "plaque forming" or "non-plaque forming." In stage 2, a new lawn of oRBC was infused, and the slide was incubated with additional anti-PTH antiserum and secretagogue. After addition of complement, cells were reindexed, and the percentage of cells that formed plaques was compared to the number of cells that did not form plaques.

\section{Results}

Inhibition of PTH by calcium: heterogeneity in the parathyroid cell population. We have previously demonstrated the validity of the RHPA to measure PTH release quantitatively from individual cells (7). We have confirmed this finding ( Fig. $1 \mathrm{~A}$ ) and determined that the plaque area, which is proportional to the amount of hormone released, decreased with increasing concentrations of extracellular calcium. We also observed that only a proportion of parathyroid cells responded to the stimulus of low extracellular calcium and quantitated these effects (Fig. $1 B$ ). At $0.1 \mathrm{mM}$ calcium, $48.5 \pm 1.7 \%$ of cells formed plaques. As extracellular calcium concentration increased, fewer cells released PTH. At $2.0 \mathrm{mM}$ calcium, only $22.9 \pm 1.8 \%$ of cells formed plaques. The half-maximal effect of this cell

\section{Table I. Sequential RHPA}

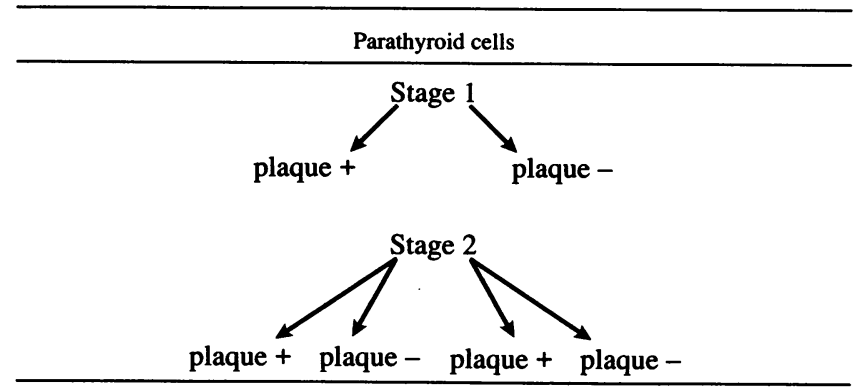


A
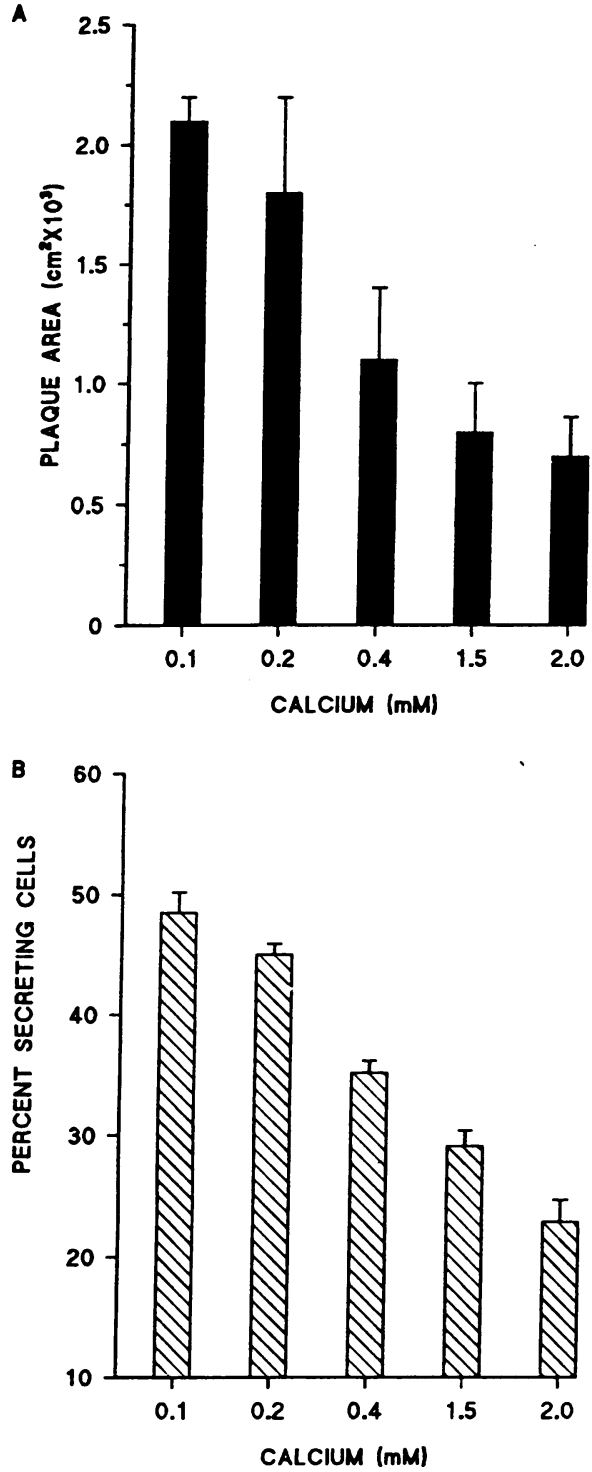

Figure 1. Effect of extracellular calcium on PTH secretion by individual cells. Bovine parathyroid cells were dispersed and plated for the RHPA as described in Methods. Cells were incubated at varying concentrations of calcium, and the amount of hormone released was determined by two methods. $(A)$ Plaque area, which is proportional to the amount of parathyroid hormone released, decreased with increasing concentrations of extracellular calcium. $(B)$ The percentage of cells forming plaques was determined as compared to the total number of cells. Only a proportion of parathyroid cells responded to the stimulus of low extracellular calcium. At $0.1 \mathrm{mM}$ calcium, $48.5 \pm 1.7 \%$ of the cells formed plaques. As extracellular calcium increased, fewer cells released PTH. At $2.0 \mathrm{mM}$ calcium, only $29.9 \pm 1.8 \%$ of cells formed plaques. Data represent mean \pm SEM of duplicate slides from 10 experiments.

secretory response was $0.4 \mathrm{mM}$, similar to that described in detail in reference 7.

Soluble poly-L-lysine has been described to alter dimerization of cell receptors and effect secretion $(12,13)$. In the RHPA, poly-L-lysine is presented in a solid phase as a plating enhancer and then washed away before plating the parathyroid/oRBC cell mixture in the Cunningham chamber. To test if cell secretion was altered by this solid-phase presentation
Table II. Comparison of Cell Attachment Substrates in the RHPA

\begin{tabular}{lcc}
\hline Attachment substrate & $\begin{array}{c}\text { Calcium } \\
\text { concentration }\end{array}$ & $\begin{array}{c}\text { Percentage of } \\
\text { plaque-forming } \\
\text { cells }\end{array}$ \\
\hline \multirow{3}{*}{ Poly-L-lysine } & $m M$ & \\
& 0.1 & 38.6 \\
Gelatin & 0.5 & 35.6 \\
& 1.0 & 33.3 \\
& 2.0 & 23.3 \\
& 0.1 & 31.0 \\
& 0.5 & 32.8 \\
& 1.0 & 39.4 \\
& 2.0 & 18.6 \\
\hline
\end{tabular}

No statistically significant differences were noted in the percentage of plaque-forming cells or the size of the plaques on slides utilizing poly-L-lysine vs. gelatin substrate.

(which is incapable of causing receptor dimerization [12]), we subbed slides with gelatin and used these slides in the RHPA. No significant differences were noted in the percentage of cells responding to calcium regardless of the attachment substrate (Table II).

Our hypothesis that the differences in cell sensitivity between the radioimmunoassay and RHPA are due to differences in the affinity and/or binding of the antibody used in the RHPA (7) was further tested in the following manner: Test tubes were coated with poly-L-lysine for $10 \mathrm{~min}$ and washed with dd $\mathrm{H}_{2} \mathrm{O}$, in a manner analogous to the preparation of the Cunningham chambers. After incubation at varying calcium concentrations, PTH concentration was determined by a sensitive immunochemiluminetric assay (8). No significant differences in PTH release was noted in dispersed parathyroid cells in control, untreated tubes vs. poly-L-lysine-treated tubes at 0.1 and $2.0 \mathrm{mM}$ extracellular calcium concentrations (data not shown).

Cell viability. One possible explanation for the lack of secretory response is the loss of cell viability during the assay. To determine that cells were viable, we determined viability in two ways. One method was a rapid, simultaneous double-staining procedure using FDA and PI. FDA-PI fluorescent staining is more consistent over prolonged periods of time (9). We also tested viability of bovine parathyroid glands at 24 and $48 \mathrm{~h}$ after their removal. The results are summarized in Table III.

Our second method of determining viability also evaluated functional status of the parathyroid cell. The sequential RHPA (described below) confirms these results. We found little differ-

Table III. Viability of Parathyroid Cells

\begin{tabular}{|c|c|c|}
\hline & \multicolumn{2}{|c|}{ Percent viable cells } \\
\hline . & $24 \mathrm{~h}$ & $48 \mathrm{~h}$ \\
\hline After trypsin digestion & 98.6 & 100 \\
\hline \multicolumn{3}{|l|}{ After RHPA incubation before } \\
\hline addition of complement* & $90.5 \pm 1.1$ & $87.8 \pm 3.2$ \\
\hline After addition of complement* & $93.4 \pm 1.0$ & $93.5 \pm 1.7$ \\
\hline
\end{tabular}

* Mean \pm SEM. 


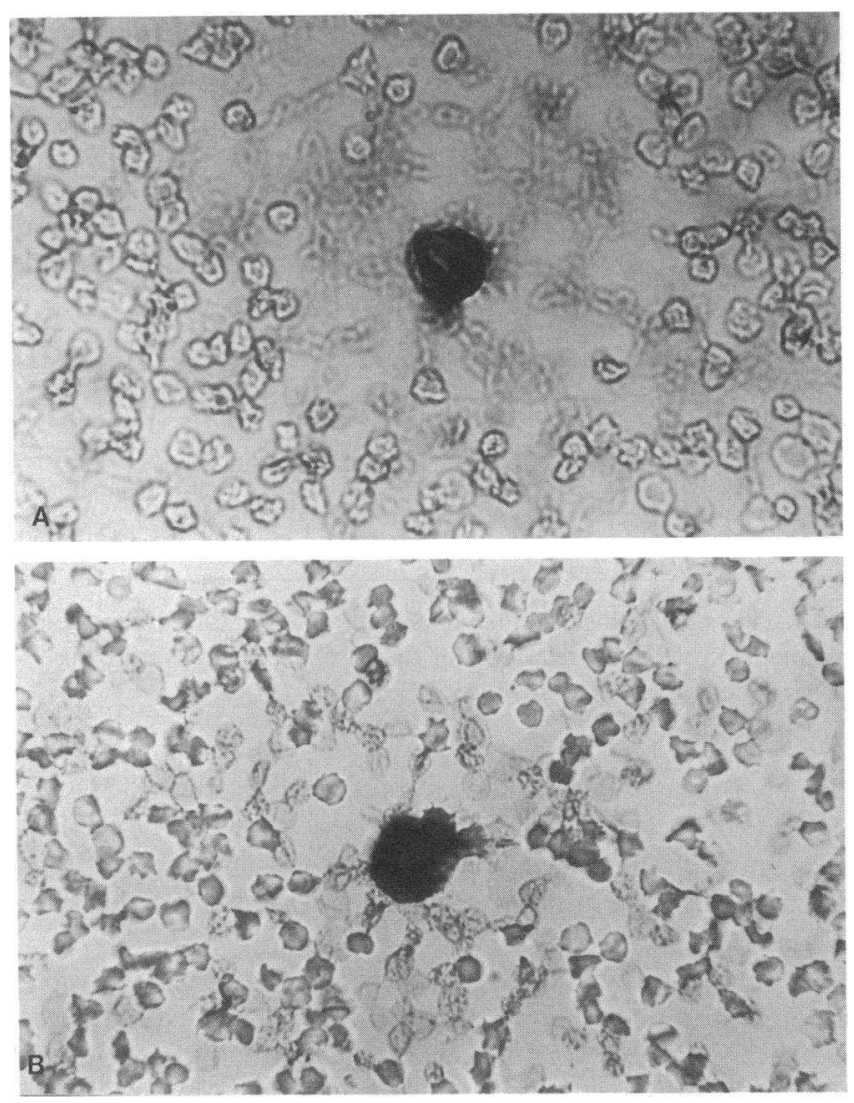

Figure 2. Immunocytochemistry for detection of PTH. To test if our dispersion technique produced more than one cell type, we combined the RHPA with immunocytochemistry to determine if stores of PTH were available for release. $(A)$ Parathyroid cell staining positive for PTH after forming a plaque in the RHPA. $(B)$ Non-plaque-forming cell that also contains adequate stores of PTH.

ence in viability during the plaque assay which would account for the heterogeneity of secretion noted above.

Immunocytochemistry. To test if our dispersion technique produced more than one cell type or that parathyroid cells were depleted of stored hormone, we combined the RHPA with immunocytochemistry to determine if stores of PTH were available for release. We have combined these two techniques and demonstrated specificity of the immunocytochemistry staining by the following criteria: Substitution of normal or preimmune serum for immune serum prevented staining; preabsorption of the PTH antiserum with bovine PTH $(1-84)(1,000 \mathrm{ng} / \mathrm{ml})$ prevented staining, and no immunostaining or plaque formation was noted in three control cell types: normal human fibroblasts, GC pituitary cells, and oRBC. Omission of PTH antiserum, the biotinylated antibody, or the $A B C$ reagents prevented immunostaining. Our results indicate that $95.2 \%$ of the cells stain positive for PTH by this method and includes virtually all $(98.6 \%)$ of the cells that did not form plaques in response to low extracellular calcium (Figs. 2 and 3 ).

In situ hybridization. The purpose of performing in situ hybridization was to test if nonsecretory cells had the capacity to synthesize PTH. Bovine parathyroid cells were placed in the RHPA, fixed, and mRNA-antisense oligonucleotides for PTH were added. After coating the slides with photographic emulsion, slides were developed, stained, and observed under dark- field microscopy. Virtually all cells in the RHPA contained mRNA for PTH as determined by this method. Cells contained mRNA for PTH regardless of plaque formation, confirming that a pure population of parathyroid cells were obtained by enzymatic digestion of the parathyroid gland. No plaque-negative cells without mRNA as detected by in situ hybridization were observed (Fig. 4). PTH cells incubated with sense oligonucleotides for PTH and nonsense probes served as negative controls.

Sequential RHPA. To determine the secretory capacity of cells that contained stores of PTH and adequate levels of mRNA for PTH, we performed a sequential RHPA. All cells were stimulated with $0.2 \mathrm{mM}$ calcium. For a positive control to test for nonspecific lysis, duplicate slides were incubated with PTH antiserum for the entire 8-h period; percentage of plaques remained the same as the 4-h incubation period ( $50.2 \pm 2.9 \%$ vs. $52.2 \pm 4.2 \%$, respectively). In stage 1 , more than half of the bovine parathyroid cells ( 165 of 254 ) responded to $0.2 \mathrm{mM}$ calcium by forming plaques and the other 89 cells did not respond (Fig. 5). Of the plaque-forming cells in stage 1, 138 cells formed plaques during stage 2 , and 27 did not respond to the second stimulus.

Of the cells that did not form plaques in stage 1,34 cells responded with plaque formation during the second stimulus. This suggests that cells that did not form plaques in stage 1 were viable and capable of secreting PTH. Of the cells in stage 2 that did not form plaques, 55 cells did not respond to a second stimulus. Viability was reassessed after this 8-h incubation and was unchanged from cell viability after the standard RHPA. In both stages 1 and 2 of the sequential RHPA, the number of plaque-positive cells was consistent (165 vs. 172). We have also successfully "turned on" cells that did not respond to the first two stimuli by a third stimulus of low extracellular calcium (data not shown). In our data analysis, the cells remain viable, and plaque-forming cells are easier to locate than non-plaqueforming cells. Therefore, our percentage of plaque-forming cells in Fig. 5 differs from Fig. 1, in which the cells are fixed and stained. For this reason, both cell number and percentage are

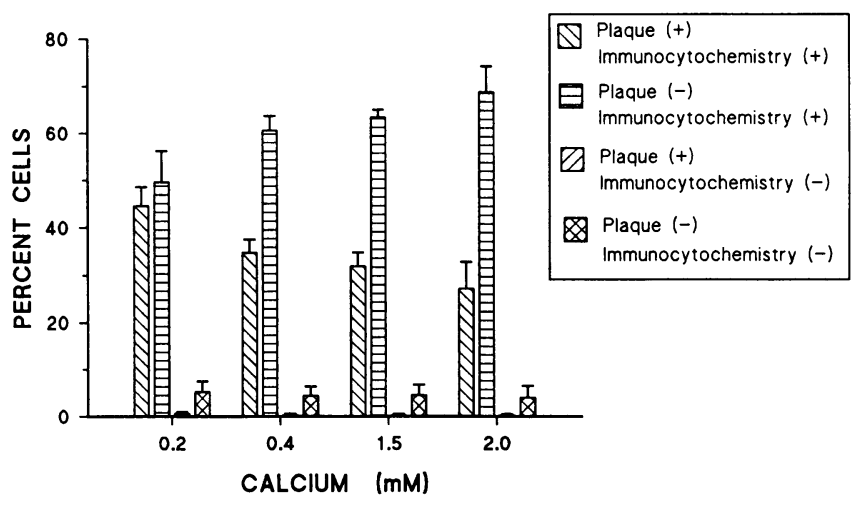

Figure 3. Quantitation of cells that contain PTH as determined by immunocytochemistry. Percentage of cells containing PTH is expressed as a function of varying concentrations of calcium. Parathyroid cells were dispersed and placed in the RHPA. After development of the RHPA, cells were cytochemically stained for PTH as in Methods. The percentage of cells forming plaques versus non-plaqueforming cells was determined at each calcium concentration indicated. Data represent the mean of three experiments performed in duplicate ( $n=1,280-1,650$ cells). 


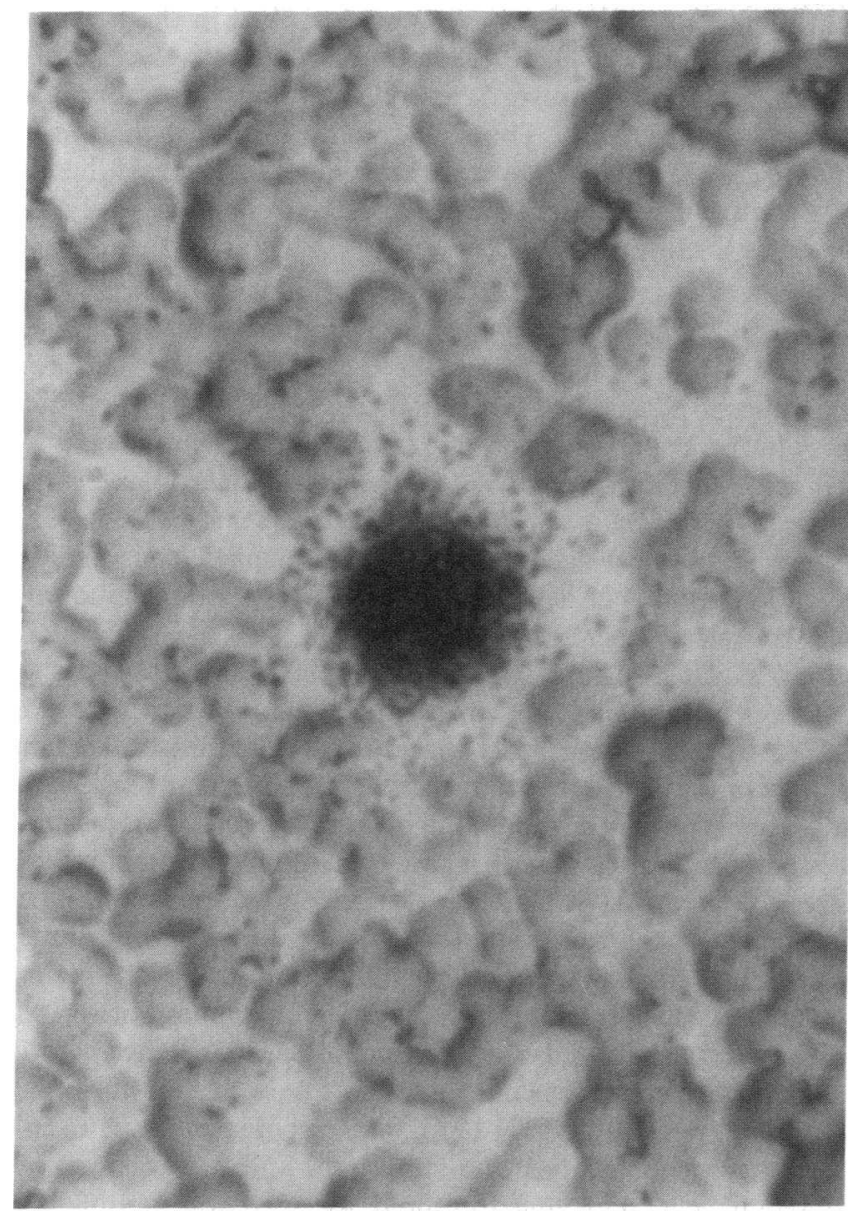

Figure 4. In situ hybridization histochemistry for PTH. Bovine parathyroid cells were placed in the RHPA and fixed, and mRNA antisense oligonucleotides for PTH were added. Cells contained mRNA for PTH regardless of plaque formation, confirming a homogeneous population of parathyroid cells were obtained by enzymatic digestion of the parathyroid gland. After incubation in low $(0.2 \mathrm{mM})$ extracellular calcium, messenger RNA for PTH was detected by in situ hybridization in both plaque-forming and non-plaque-forming cells. This photomicrograph demonstrates a typical non-plaque-forming cell that is positive for PTH mRNA.

expressed on Fig. 5. However, the concept that cells are nonplaque-forming and can be turned "on" to form plaques is clearly evident in this experiment.

\section{Discussion}

Bovine parathyroid cells responded to changes in extracellular calcium in a heterogenous manner. Each experiment allowed measurement of two parameters of cell secretion: the area of the hemolytic plaque which is proportional to the amount of PTH secreted and the number of cells forming plaques as compared to the total number of cells present. Both the amount of PTH released per cell and the number of cells responding to extracellular calcium increased with decreasing extracellular calcium levels. Several explanations for this functional heterogeneity are possible; we examined many of these reasons.

The heterogenous response to extracellular calcium created many new questions, especially in regards to the technique used in this investigation. Many of the issues regarding cellular sensitivity as compared to an radioimmunoassay have been addressed previously (7). However, cell viability was one possible problem, as only half of the parathyroid cells appeared to respond to low concentrations of extracellular calcium. We tested viability by two methods which determined that the cells were viable and capable of secretion.

Certain fluorescein dyes are more reliable indicators of cell viability than the traditional colored dyes $(9,14)$. The intercalating dyes such as PI passes through the membrane of dead or dying cells, and fluorochromasia is well characterized as a property of living cells (15). FDA, a nonpolar ester, passes through the cell membrane and is hydrolyzed by intracellular esterases to produce fluorescein. The fluorescein accumulates in the cell and exhibits a bright green fluorescence when excited by blue light. Cell injury results in the inability of the cell to exhibit fluorochromasia and the dye itself is not toxic. Thus, FDA stains viable cells exclusively (9). In contrast, dead and injured cells are stained by PI, which passes through the damaged cell membrane and intercalates with DNA and RNA. The resultant observation is a bright red fluorescence in the nuclei of dead cells. In nonviable cells, which have leaky membranes, the fluorescein will be unable to accumulate in sufficient quantity to exhibit fluorochromasia $(16,17)$. This method is so stable that reliable estimates of cell viability can be made $1 \mathrm{wk}$ after preservation of the cells (9). In our RHPA, we found consistent levels of viability during each step of the procedure.

The second method of testing viability is inherent in the sequential RHPA, in that cells that were not capable of secretion of PTH will respond to a second stimulus (see below). Our double or triple sequential plaque assay indicated that cells that are not actively secretory at one time point can respond to a stimulus at a later time point.

The purity of cell dispersion is always questionable in cell population secretory studies. In this study, we have clearly demonstrated that parathyroid cells that are not releasing PTH in response to low calcium concentrations contain adequate

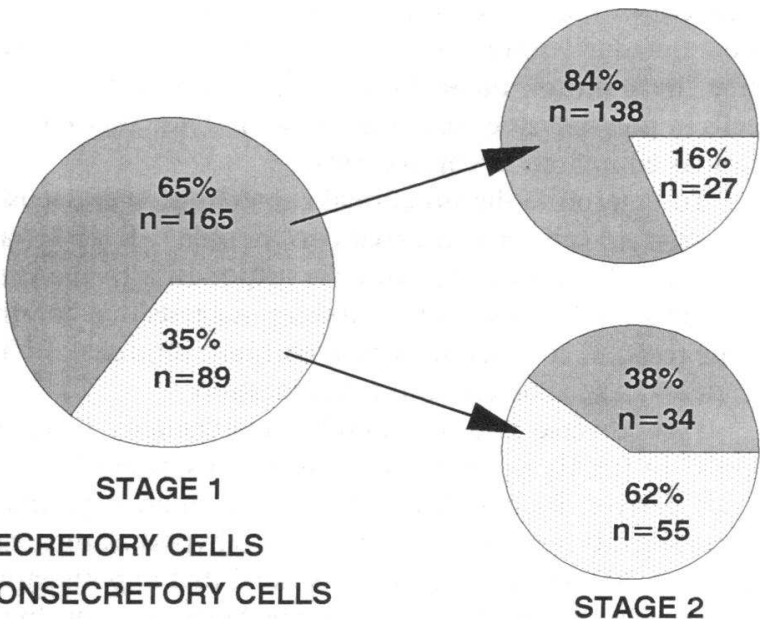

Figure 5. The sequential RHPA assay: ability of stage 1 cells to form plaques in stage 2 . Bovine parathyroid cells were plated for the RHPA. Anti-PTH was used as the stage 1 antibody and the stage 2 antibody. In stage 1, 165 of 254 of the cells indexed secreted PTH, and of these, 138 formed plaques during stage 2. Of the cells unable to secrete PTH during stage 1, 34 secreted PTH during stage 2. 
stores of PTH as detected by immunocytochemistry. We believe that our staining is specific for PTH as staining was prevented by substitution of preimmune serum, preabsorption of PTH antiserum with bovine PTH (1-84), and the lack of staining in normal human fibroblasts, GC pituitary cells, or the surrounding ovine erythrocyte lawn.

Endothelial cells are known to phagocytose catecholamines (18), and it has been proposed that endothelial cells near the parathyroid may also endocytose PTH (19). Therefore, these endothelial cells may be confused with parathyroid cells (plaque forming or non-plaque forming) by immunocytochemical techniques. We performed in situ hybridization to determine the percentage of cells that contained mRNA for PTH. Virtually all cells contained mRNA for PTH, thus confirming both the purity of the cell preparation and the ability of non-plaque-forming cells to synthesize PTH.

We have previously compared the RHPA to the traditional measurement of PTH in cell supernatants by radioimmunoassay (7). Others have carefully examined the effects of our plating cell substrate, poly-L-lysine, on cell secretion (13). Cationic polymers such as D-Lys, L-Lys, and L-Arg stimulate LH release under extraordinarily specific conditions (12). The fact that positively charged amino acid polymers stimulate $\mathrm{Ca}^{2+}$-dependent gonadotropin release from pituitary cell cultures is not due to lysis of the polylysine, is independent of the molecular weight of the polymer, is independent of the amino acid utilized, and is dependent on the soluble phase of the polymer. However, this effect is charge dependent because masking the charge on internally charged polymers is without effect. In addition, the minimal and maximum spacing between charges is important suggesting that these effects are possibly mediated at the cell surface. These effects on cell secretion have been confirmed in parathyroid cells (13). However, the RHPA does not contain soluble, charged amino acid polymers that could affect the secretory response to calcium. The poly-L-lysine substrate is placed on the slide for $10 \mathrm{~min}$ and washed off before plating the parathyroid/oRBC mixture (7). To be certain that poly-Llysine did not alter cell secretion in the RHPA, we subbed slides with $1 \%$ gelatin, a stable substrate for cell attachment. No differences in the plaque area or the number of secretory cells were noted as compared to control slides containing poly-L-lysine. In addition, incubation of a population of parathyroid cells in poly-L-lysine coated test tubes did not alter PTH secretion as compared to control cells.

To determine the functional capabilities of single isolated parathyroid cells, a sequential (or "double") RHPA was performed. The consistency of cells responding to the first and second stimulus by plaque formation suggests that parathyroid cells respond to calcium with a constant amount of PTH secreted at a specific calcium concentration.

How diverse is this secretory heterogeneity in endocrine cells? In freshly isolated rat pituitary cells, prolactin-secreting cells derived from separate regions of anterior pituitaries of lactating rats respond differently to two hypothalamic releasing factors (20). It has been demonstrated that hypothalamic factors can be delivered to circumscribed regions of the hypophysis in different concentrations. It is possible that the heterogeneity in the parathyroid cell could be related to regional variations in the parathyroid gland. However, this is less likely in the parathyroid gland than in the pituitary, where the hypothalamus has a marked effect on the structure and function of the pituitary gland.
"Silent" somatotropes have been described in the bovine pituitary gland (2). These cells do not constitutively release growth hormone; however, they release growth hormone in response to stimulation. The silent somatotropes, like the parathyroid cells in this study, were capable of storage and synthesis of growth but were unable to release their contents until induced by a stimulatory agent.

Under the conditions of varying calcium concentrations, only a fraction of the bovine parathyroid cells in this assay release PTH. As with pituitary cells (2), this could be related to the concept of the readily releasable pool of hormone. This term in this context refers to the fraction of total bovine parathyroid cells that respond to low but physiologically relevant calcium concentrations. The possibility exists that addition of a second stimulatory agent, such as a $\beta$-adrenergic agonist, may recruit additional cells to secrete and/or increase the amount of PTH released per cell.

Jia et al. $(3,4)$ have described differing sensitivities of corticotropes in response to corticotropin releasing factor and ACTH. These investigators suggest that functionally distinct classes of corticotropes are present, with particular sensitivity to secretagogues or combination of secretagogues. This plasticity of corticotrope response may maintain adaptability to stressful situations. The same plasticity of response may be important in the parathyroid gland, where minute-to-minute response to changes in serum calcium are critical for the maintenance of calcium homeostasis. A second hypothesis proposed by Leong is that an activation threshold must be reached before a corticotrope can respond to corticotropin release hormone with the release of ACTH (21). The response of tissue to increasing concentrations of a stimulus could be explained by different cells achieving threshold for secretion at different times.

Other cells have been found to respond to secretogogues in a functionally heterogeneous manner. Poenie and colleagues (22) measured intracellular calcium response in two newly formed daughter cells. In spite of synchronization of cell cycle and genetic similarities, these cells responded differently to similar secretagogues.

The variation in parathyroid cell response to calcium may provide a secretory reserve in the cell in order to respond to a second or third stimulus. Roth and Raisz (23) proposed a secretory cell cycle of the parathyroid gland based on morphology of secretory granules. These investigators described several phases of cell secretion including a synthesizing phase, a transferring phase, a packaging phase, a secreting phase, an involuntary phase, and a resting phase. Confirmation of this hypothesis was produced by ultrastructural studies of human parathyroid tissue by Shannon and Roth (24). Our data support the basic premise of this hypothesis in that not all parathyroid cells are capable of responding to a stimulus at a particular time. This suggests that there will always be a definitive number of cells that are synthesizing and releasing hormone. This concept is augmented by the demonstration of a nonsuppressible component of PTH secretion (6). It is also possible that the heterogeneous cell response reflects the physiologic episode fluctuations in serum PTH in humans. Kitamura et al. (25) described a circadian rhythm in serum intact PTH, and this finding has been confirmed by others (26). Distinct episodic pulses of PTH were determined by Cluster analysis with temporal coupling to serum calcium concentrations. This circadian rhythm is lost in primary hyperparathyroidism (27). It is possible that 
the secretory cycling that occurs in vitro reflects the physiologic in vivo response of the parathyroid gland to repeated alterations in serum calcium.

\section{Acknowledgments}

The authors express their gratitude to Dr. Larry Mallette and Dr. Claude Arnaud for provision of antisera, Dr. Cheryl Conover for provision of fibroblasts and Dr. N. Eberhardt for provision of GC pituitary cells, Dr. B. L. Riggs for careful review of the manuscript, Dr. M. Parfitt for his helpful discussions, and Mrs. Mary Craddock for expert secretarial assistance.

This study was supported in part by grants DK-42572 and DK42802 from the U. S. Public Health Service.

\section{References}

1. Frawley, L. S., and J. D. Neill. 1984. A reverse hemolytic plaque assay for microscopic visualization of growth hormone release from individual cells: evidence for somatotrope heterogeneity. Neuroendocrinology. 39:484-487.

2. Kineman, R. D., W. J. Faught, and L. S. Frawley. 1990. Bovine pituitary cells exhibit a unique form of somatotrope secretory heterogeneity. Endocrinology. 127:2229-2235.

3. Jia, L. G., B. J. Canny, D. N. Orth, and D. A. Leong. 1991. Distinct classes of corticotropes mediate corticotropin releasing hormone- and arginine vasopressin-stimulated adrenocorticotropin release. Endocrinology. 128:197-203.

4. Jia, L. G., B. J. Canny, and D. A. Leong. 1992. Paracrine communication regulates ACTH secretion. Endocrinology. 130:534-539.

5. Porter, T. E., C. D. Wiles, and L. S. Frawley. 1991. Evidence for bidirectional interconversion of mammotropes and somatotropes: rapid reversion of acidophilic cell types to pregestational proportions after weaning. Endocrinology. 129:1215-1220.

6. Mayer, G. P., J. F. Habener, and J. T. Potts. 1976. Parathyroid hormone secretion in vivo. J. Clin. Invest. 57:678-683.

7. Fitzpatrick, L. A., and D. A. Leong. 1990. Individual parathyroid cells are more sensitive to calcium than a parathyroid cell population. Endocrinology. 126:1720-1727.

8. Klee, G., C. M. Preissner, P. G. Schryver, R. L. Taylor, and P. C. Kao. 1992. Multiple site immunochemiluminescent assay for simultaneously measuring whole-molecule amino terminal fragment of human parathyroid hormone. Clin. Chem. 38:628-35.

9. Jones, K. H., and J. A. Senft. 1985. An improved method to determine cell viability by simultaneous staining with fluorescein. J. Histochem. Cytochem. 33:77-79.

10. Uhl, G. R. 1989. In situ hybridization: quantitation using radiolabeled hybridization probes. Methods Enzymol. 168:741-752.
11. Smith, P. F., E. H. Luque, and J. D. Neill. 1986. Detection and measurement of secretion from individual neuroendocrine cells using a reverse hemolytic plaque assay. Methods Enzymol. 124:443-465.

12. Conn, P. M., D. C. Rogers, S. G. Seay, and D. Staley. 1984. Activation of luteinizing hormone release from pituitary cells by polycations. Endocrinology. 115:1913-1917.

13. Brown, E. M., C. Katz, R. Butters, and O. Kifor. 1991. Polyarginine, polylysine, and protamine mimic the effects of high extracellular calcium concentration on dispersed bovine parathyroid cells. J. Bone Miner. Res. 6:1217-1225.

14. Black, L., and M. C. Berenbaum. 1964. Factors affecting the dye exclusion test for cell viability. Exp. Cell Res. 35:9-13.

15. Rotman, B., and B. W. Papermaster. 1966. Membrane properties of living mammalian cells as studied by enzymatic hydrolysis of fluorogenic esters. Proc. Natl. Acad. Sci. USA. 55:134-141.

16. Edidin, M. 1970. A rapid, quantitative fluorescence assay for cell damage by cytotoxic antibodies. J. Immunol. 104:1303-1306.

17. Krishan, A. 1975. Rapid flow cytofluorometric analysis of mammalian cell cycle by propidium iodide staining. J. Cell Biol. 66:188-193.

18. Banerjee, D. K., R. L. Ornberg, M. B. H. Youdim, E. Heldman, and H. B. Pollard. 1985. Endothelial cells from bovine adrenal medulla develop capillarylike growth patterns in culture. Proc. Natl. Acad. Sci. USA. 82:4702-4706.

19. Brandi, M. L., R. L. Ornberg, K. Sakaguchi, F. Curcio, A. Fattorossi, P. I Lelkes, T. Matsui, M. Zimmering, and G. D. Aurbach. 1990. Establishment and characterization of a clonal line of parathyroid endothelial cells. FASEB (Fed. Am. Soc. Exp. Biol.) J. 4:3152-3158.

20. Boockfor, F. R and L. S. Frawley. 1987. Functional variations among prolactin cells from different pituitary regions. Endocrinology. 120:874-879.

21. Leong, D. A. 1988. A complex mechanism of facilitation in pituitary ACTH cells: recent single-cell studies. J. Exp. Biol. 139:151-168.

22. Poenie, M., J. Alderton, R. Tsien, and R. Steinhardt. 1985. Changes of free calcium levels with stages of the cell division cycle. Nature (Lond.). 315 147-9.

23. Roth, S. I., and L. G. Raisz. 1966. The course and reversibility of the calcium effect on the ultrastructure of the rat parathyroid gland in organ culture. Lab. Invest. 15:1187-1211.

24. Shannon, W. A., and S. I. Roth. 1974. An ultrastructural study of acid phosphatase activity in normal, adenomatous and hyperplastic (chief cell type) human parathyroid glands. Am. J. Pathol. 77:493-506.

25. Kitamura, N., C. Shigeno, K. Shiomi, K. Lee, S. Ohta, T. Sone, S. Katsushima, E. Tadamura, T. Kousaka, I. Yamamota, et al. 1990. Episodic fluctuation in serum intact parathyroid hormone concentration in men. J. Clin. Endocrinol. Metab. 70:252-263.

26. Calvo, M. S., R. Eastell, K. P. Offord, and E. J. Bergstrahl. 1991. Circadian variation in ionized calcium and intact parathyroid hormone: evidence for sex differences in calcium homeostasis. J. Clin. Endocrinol. Metab. 72:69-76.

27. Logue, F. C., W. D. Fraser, D. S. J. O'Reilly, D. A. Cameron, A. J. Kelly, and G. H. Beastall. 1990. The circadian rhythm of intact parathyroid hormone(1-84): temporal correlation with prolactin secretion in normal men. J. Clin. Endocrinol. Metab. 71:1556-1560. 